\title{
Attitudes Toward Science Among School Students Of Different Nations: A Review Study
}

Riffat-Un-Nisa Awan, University of Sargodha, Pakistan Muhammad Sarwar, University of Sargodha, Pakistan Anjum Naz, University of Sargodha, Pakistan Ghazala Noreen, Lahore College University, Pakistan

\begin{abstract}
This review examines the effects of nationality on attitudes of students to study science. It compares data from many countries published in refereed research journals, research reports, book chapters, and conference papers. The main aim is to identify the commonalities and variations in the students' attitudes with particular focus on students from developing and developed countries. The search of bibliographical databases yielded a lot of researches. After title and abstract screening and after eliminating duplicates and applying inclusion criteria, this search ended up to include 15. Findings make it clear that students in different parts of the world develop differing attitudes toward science. It is observed that students are positive internationally; however, students in developing countries are more positive than the students in rich and developed countries, especially in Japan and Korea. Biology is most favourite, particularly of girls, whereas boys favour physics. It is also felt that comparing available attitude data is not simple and must be done with caution.
\end{abstract}

Keywords: Attitude; Science; Nationality; School Students

\section{INTRODUCTION}

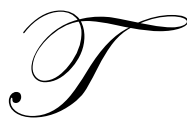

his study explores the attitude of students toward science, their interest, motivation and satisfaction with the subjects at school in different parts of the world. The context of this review study is the problem that the number of students who are taking science subjects at secondary and higher secondary level is declining and most of them discontinue studying science whenever they have a choice (Lyons, 2006). According to a report of House of Commons (2002), students' interest in school science is declining with an accompanied declining number of students taking science, which consequently causes shortage of science literates in different science-based professions. Lyons' (2006) summary indicates that enrolment rates in the natural sciences have been steadily declining in Australia, Canada, India, Japan, and the USA, as well as nearly every country in the European Union. So, it is the need of the day to get a broader picture of the reasons that hinder learners from entering this field and developing a less positive attitude over time. A comparative investigation between nations about pupils' affective dispositions toward the learning of school science could be a good starting point to move in this direction.

In the database of attitude research, there are some very comprehensive review studies, like 'Gender Differences in Student Attitudes Toward Science: A Meta-Analysis of the Literature from 1970 to 1991' by Weinburgh (1995), 'Attitudes Towards Science: A Review of the Literature and its Implications' by Osborne, Simon, \& Collins (2003), and 'In Pursuit of Validity: A Comprehensive Review of Science Attitude Instruments 1935-2005' by Blalock et al (2008). The present review is different as it tries to uncover the holistic picture of attitude variations across the developed and developing countries of the world. It tries to determine if cultural orientation affects the attitude of pupils. The purpose of the study is to identify the commonalities and variations in 
students' attitudes and their interest in science in relation to whether they are from developing or developed countries.

\section{METHODS}

For this review, only the cross-national comparative studies were considered for analysis. These were chosen because direct comparison of the findings from different sources was not straight forward due to differences in sampling, instruments, methodology, and the way in which the findings were presented.

The selection of the studies for this review was made on the basis of the following general criteria made and adopted by the researchers with the help of the experts:

1. It was first determined whether the study was about the attitudes of students toward science and it was conducted in a comparative perspective across the nations.

2. It was decided to include studies that explored the attitudes of students to study science - in general, physics, chemistry, and biology as subject areas. ICT and earth science were not included in the review.

3. The review was restricted to contributions between 1990 and 2008 from the discipline of science education.

4. Only those researches that focused on school population were included for analysis.

The process of searching peer-refereed research papers involved the following specific steps: First, bibliographical databases (Australian Education Index, British Education Index (BEI), PsychInfo, ProQuest, Google Scholar, and ERIC) were searched for relevant peer-refereed journal articles and books using specific search queries. The search terms used were 'attitudes', 'science', 'school', and 'cross-cultural comparisons'. Secondly, the reference lists of the researches that resulted from this search activity identified additional important reports, journals, books, and key researches in this area of interest, which were, in turn, included in the review process. Finally, search engine Google was used to obtain two conference papers.

These searches returned thousands of hits. Of these, the title screening was done with 692 for their relevance to the topic. All those dealing with single country population and on topics insufficiently relevant to this project were discarded. Resultantly, abstracts of 87 studies were screened and the studies not directly talking about attitude, but chiefly discussing achievement, were excluded, resulting in 56 potential studies. After elimination of 11 duplicate results, four papers not retrieved, and excluding the 14 studies that came under exclusion criteria after full text screening, the resulting number of papers was 27. Initially, mathematics was also a part of this review, but later on - because of the volume of this writing - mathematics studies (which were 12 in total) were excluded. The resulting number was 15 , which were finally included for analysis. Table 1 shows a list of included studies and more details.

Table 1: Summary of the Studies Included in the Review

\begin{tabular}{|c|c|c|c|c|}
\hline Sr.No & Author & Year & Title & No of Countries \\
\hline 1. & Beaton, et al & 1996 & Mathematics and Science Achievement in the Middle -- & 38 \\
\hline 2. & Leung, F.S. & 2002 & Behind the High Achievement of East Asian Students & 4 \\
\hline 3 . & Lyons, $\mathrm{T}$. & 2006 & Different Countries, Same Science Classes: Students' - & 3 \\
\hline 4. & Martin, et al & 1997 & Science achievement in the primary school years: IEA 's--- & 26 \\
\hline 5. & Martin, et al & 2000 & TIMSS 1999 International Science Report: Findings from-- & 38 \\
\hline 6. & Martin, et al & 2004 & TIMMS 2003 International Science Report Findings From- & 46 \\
\hline 7. & Martin, et al & 2008 & TIMMS 2007 International Science Report Findings From- & 59 \\
\hline 8. & Mullis, et al & 1998 & Mathematics and science achievement in the primary - & 26 \\
\hline 9. & Murphy et al & 2006 & Middle East meets West: Comparing children's attitudes - & 2 \\
\hline 10. & Murphy, and Beggs & 2001 & Pupils' attitudes, perceptions and understanding of --- & 2 \\
\hline 11. & OECD & 2006 & PISA 2006 Science Competencies for Tomorrow's World & 56 \\
\hline 12. & $\begin{array}{l}\text { Papanastasiou, and } \\
\text { Michalinos }\end{array}$ & 2004 & $\begin{array}{l}\text { Differential effects of science attitudes and science } \\
\text { achievement in- }\end{array}$ & 3 \\
\hline 13. & Schreiner, \& Sjøberg. & 2007 & Science education and youth's identity construction - two -- & 25 \\
\hline 14. & Sjøberg, S. & 2002 & Science for the children? Report from the Science and--- & 21 \\
\hline 15. & $\begin{array}{l}\text { Ye, Wells, Talkmitt, \& } \\
\text { Ren }\end{array}$ & 1998 & $\begin{array}{l}\text { Student Attitudes toward Science Learning: A cross- } \\
\text { National -- }\end{array}$ & 2 \\
\hline
\end{tabular}


The methodology carries with it some limitations. As cross-country comparative research involves a lot of resources on the part of the researcher, the number of studies is very small in this field. Secondly, it is dependent on large-scale studies which rely on survey data collected using questionnaires only. It has little qualitative data, so an in-depth investigation using qualitative techniques is missing from this review and also misses out on answering the questions related to why people are not interested in science and how it may be possible to increase interest in science. This is the reason why these research questions cannot be posed and answered.

\section{FINDINGS}

These references are discussed mainly under sections entitled Attitude toward General Science and Attitude toward Physics, Chemistry and Biology.

\section{Attitude toward General Science}

It is found that attitudes are not the same. They vary remarkably in different parts of the world and a student's nationality does affect his attitude (Ye, Wells, Talkmitt, \& Ren, 1998). The first striking finding is that compared to developed countries, children in developing countries appear to be more interested in science and science-related topics. On the other hand, students in developed countries show little interest in the subject (Beaton, Martin, Mullis, Gonzales, Smith \& Kelly, 1996; Martin, Mullis, Beaton, Gonzalez, Smith \& Kelly, 1997; Martin, Mullis, Gonzalez \& Chrostowski, 2004; Martin, Mullis \& Foy, 2008; Mullis, Martin, Beaton, Gonzalez, Kelly \& Smith, 1999; OECD, 2006; Sjøberg, 2002; and Schreiner \& Sjøberg, 2007).

Table 2: Students' High and Low Attitudes in Developed and Developing Countries in TIMSS, PISA, ROSE and SAS

\begin{tabular}{cll}
\hline $\begin{array}{c}\text { Level of } \\
\text { interest }\end{array}$ & \multicolumn{1}{c}{ Research Studies } & \multicolumn{1}{c}{ Name of Countries } \\
\hline Low & & Developed Countries \\
\hline 1 & Sjoberg, 2002 & Norway, Sweden \& Iceland \\
2 & Schreiner \& Sjøberg, 2007 & England, Norway, Denmark, Sweden, Iceland, Finland \& Japan. \\
3 & Beaten et.al 1996 & Australia, Israel, Korea and Japan. \\
4 & Martin et. al 1997 & Netherlands. Latvia, Ireland, Canada. \\
5 & Mullis et al 1999 & Australia, Hong Kong, Korea and Japan. \\
6 & Martin et al 2004 & Hong Kong, Australia, Norway, Italy, Chinese Taipei, Korea, Japan. \\
7 & OECD, 2006 & Australia, Israel, Denmark, Sweden, Iceland Finland, Netherlands, Korea and Japan. \\
8 & Martin et al 2008 & Italy, Australia, Japan, Chinese Taipei, Korea, and Spain \\
\hline High & & Developing Countries \\
\hline 1 & Sjøberg 2002 & Nigeria, Philippines, India, New Guinea and Uganda. \\
2 & Schreiner \& Sjøberg, 2007 & Uganda, Ghana, Philippines, \& India, Botswana. \\
3 & Beaton, 1996 & Iran Kuwait, Singapore, Thailand and Columbia \\
4 & Martin et al 1997 & Iran and Kuwait \\
5 & Mullis et al 1999 & Malaysia, Philippines, Tunisia, \& Jordon \\
6 & Martin et al 2004 & Botswana, Egypt, Ghana, Jordan \& Tunisia. \\
7 & OECD, 2006 & Columbia, Mexico, Jordan, Kyrgyzstan, Thailand and Tunisia. \\
8 & Martin et al 2008 & Tunisia, Botswana, Colombia, Oman, Egypt, and Ghana. \\
\hline
\end{tabular}

Table 2 lists the names of countries with high and low percentages of students with positive attitudes toward science. It illustrates that the students in developed countries show little interest in the subject as compared to the interest expressed by children in developed countries.

An analysis of studies selected for this review also makes it clear that overall, internationally, students show their interest in science. This is evident from the results of PISA 2006 with an average of $63 \%$ of the students reporting that they are interested in science and have fun doing so. This result is consistent with TIMSS 2003 where the international average of eighth graders having a highly positive attitude $(57 \%)$ and $31 \%$ in the medium category. Only 12\% of the students are in the low category. TIMSS 1999 gives the figures of $40 \%, 49 \%$, and $10 \%$, respectively, for the same variable. In TIMSS 2007, 65\% of eighth grade students are at the high level of the positive 
affect index, compared to $19 \%$ at the medium level and $16 \%$ at the low level. This means that although a certain percentage of students do not express their high liking for school science, the subject does attract the curiosity of many students and retains them in the field. This is also true for the US, England and Germany, as almost all largescale projects place them in a reasonably better position compared to students in Japan and Korea and some other European countries.

However, the picture is not badly bleak for developed nations, since in the majority of the countries, the average scores for both girls and the boys are on the positive side and only one out of 25 countries is below average/midpoint in the ROSE study. Likewise in TIMMS studies, more than 50\% are in the high and medium category of liking the subject. No doubt, PISA is showing less than a 50\% average score for some of these countries, but all of them are above $40 \%$.

As far as small-scale studies are concerned, findings from Murphy \& Beggs' (2001) study indicate that eight to eleven year old pupils in Northern Ireland significantly display more positive attitudes (at $\mathrm{p}<0.05 \%$ ) to school science than those from schools in the English sample. The Northern Ireland pupils also seem to be more confident than the English pupils in their science ability. Likewise, students in Cyprus are slightly more positive toward science than the US, followed by Australian students, as explored by Papanastasiou \& Michalinos (2004) who have tried to examine the spatial locality of the attitude-achievement relationship in a cross-cultural context using TIMSS data.

Murphy and Beggs (2001) and Murphy, Ambusaidi,\& Beggs (2006) try to determine changes in enjoyment of science over time between Oman, English, and Northern Ireland students. The results demonstrate that nine year old children show significantly more positive responses to the statements relating to enjoyment of science than the older students, especially in the Omani and the Ireland samples. This is also clear in TIMSS (1995) as results showed $44 \%$ of the fourth graders were enjoying the subject compared to $23 \%$ eighth graders. In 2003 , these percentages were $55 \%$ and $44 \%$, respectively, which shows a clear indication of attitude decline with age and grade level.

Lyons (2006) reviews three studies - Lindahl's longitudinal study in Sweden, Osborne and Collins' focus group interviews in England, and Lyons surveying and then conducting a series of individual interviews of students and teachers in Australia. He quotes that the most common remarks by the English, Australian, and Swedish pupils are that science content is often boring and irrelevant to students' interests and aspirations without trying to engage their interest or establish relevance with familiar "every-day life" contexts, just like US students who think there is too much memorization (Ye et al, 1998). Lyons reports that in Sweden and Australia, "students turn to non-science subjects to satisfy interests that should be catered by science courses" (Lyons, 2006, p. 599). More than one in five of the high-achieving students in Australia, including many who intend to continue the study of science, used the term "boring" to characterize their science classroom experiences. In Sweden, boredom with the course content is so prevalent that even students who initially aspire careers involving science, eventually decide that "science is so boring they have given it up" (Lyons, 2006, p.600). It is very important to note that the students are being put off because of the less interesting and hard content which forces the students to cram and memorize and makes them disinterested in the subject, thus go for other attractive options.

An important finding in this regard is that East Asian pupils indicate a remarkably low interest in science, the girls in particular. Japan, Korea, China, and Hong Kong usually come out on the top in international comparisons on science achievement tests, but lowest on attitude and self-concept scales, and not particularly liking science (Beaton et al. 1996; Leung, 2002; Martin, Mullis, Gonzalez, Gregory, Smith, Chrostowski, et al., 2000; Martin et al, 2004; OECD, 2006; Sjøberg, 2002; Schreiner \& Sjøberg, 2007; and Ye, et al, 1998). This response, which is called "Japanese paradox" by Schreiner \& Sjøberg (2007), is interesting. In light of the fact that Japanese and Korean children out-perform the children of the world, as a whole, with a remarkable difference and big impressive proportion, of the top $10 \%$ of students (Smith, Martin, Mullis \& Kelly, 2000), only a small proportion of children find science easy to understand and they have more negative attitudes to both mathematics and science than pupils in any other participating country. Although TIMSS 2007 displays an increased percentage of Korean and Japanese students in the high level of positive attitudes (compared to their percentage of students in TIMSS 1995 
and 1999), which is a very positive sign for these nations, compared to other nations, they are still very low in their attitude scores (Martine, 2008).

The low interest results are very important for the high-performing nations as the PISA study found a strong association between students' general interest in science and their performance in France, Japan, Korea, Switzerland, and Finland (35 to 31 score points). If the students are kept disinterested for a long period of time, it may very adversely affect the performance of the students in advanced countries.

\section{Attitude toward Physics, Chemistry and Biology}

Attitudes toward science subject areas are not explored to great lengths because up until eighth grade, science is taught as an integrated subject everywhere, with the exception of a few countries, such as Netherlands, Belgium, Hungry, Czech Republic, Russian Federation, and some other eastern European countries. PISA 2006 and TIMSS are the only international comparative studies that separately investigate attitudes toward science subject areas, while SAS tries to explore the same by analyzing the writings of 828 students under the heading 'Me as Scientist' and mainly analyzing data from three countries - England, Nigeria, and Norway.

Countries like Macedonia, Bulgaria, Moldova, and the Russian Federation in TIMSS 1999 and Armenia, Macedonia, Moldova, and Indonesia and Lebanon in TIMSS 2003 have relatively large percentages of students in the high level attitude index in almost all subject areas. Serbia has the highest percentage in the high category of positive attitude index for biology, the Slovak Republic in chemistry, and the Russian Federation in physics. Romanian students show the most positive attitude in biology, but they are less positive in physics and chemistry.

Similarly, there are differences in the degree of liking for the different science disciplines in the final year of secondary school. TIMSS data illustrate an increase in percentage of students in biology and chemistry, with greater percentages of students in 2003 than in 1999.

In countries teaching the sciences as separate subjects at the eighth grade level, attitudes are most positive toward biology (32\% in the high category) and least positive toward chemistry and physics - 23 and 10\%, respectively (Martin et al, 2000). The same is the case in TIMSS 2003 with a bit improved percentages, as greater percentages of students are in the high index category for biology (37\%) and physics (31\%) and lower percentages for chemistry (29\%). TIMSS 2007 shows a big increase in percentage of students who are in the high index level in biology (66\%) and in chemistry and physics (both 50\%).

Fifteen year olds in the PISA 2006 study show a similar picture as the majority of students (68\% on average) report an interest in human biology and they report less interest in astronomy, chemistry, physics, the physiology of plants, and the ways in which scientists design experiments (between 46 and 53\% on average). In SAS, it is noted that biological topics are popular in all three countries; chemistry is not mentioned very often, except by Nigerian girls; and physics does not appear to be a popular research priority for any of the groups in this analysis.

Papanastasiou \& Michalinos (2004) explain a different picture as their findings indicate that liking biology and chemistry is significantly and positively correlated and is negatively correlated with liking physics. It may indicate that the concepts of chemistry and biology may have similar elements that appeal to many students. Moreover, liking a particular subject can be traced to the perception of students and their peers about the subjects with regard to easy/hard and interesting/boring content. Perhaps this may be one reason why students opt for more biology and less physics, but not for the Chinese students who are more interested in physics as compared to US students who like chemistry (Ye, et al 1998). US students have strong positive relationships between science attitude and liking of all three subject areas, as compared to Cyprus and Australia (Papanastasiou \& Michalinos, 2004), but more US students like biology as compared to Australia and Cyprus students, although the difference is marginal. Students of all three countries like biology more than chemistry and chemistry more than physics, except Cyprus students where $48 \%$ like physics and $42 \%$ like chemistry. 


\section{Gender Difference}

Findings of these studies for science subject areas indicate a strong inclination of girls toward biology and boys toward physics and chemistry (Martin et al, 2000, Mullis et al, 1998; and Sjøberg, 2002). Similarly, in the final year of secondary school, in many countries, female students report liking biological science and disliking physics to some degree. The same is found for eighth graders in all countries where male students report liking physics significantly more than female students. Female students in nearly all countries report disliking physics to some degree, while male students are more neutral in their attitudes (Mullis et al, 1998).

Sjøberg's (2002) study reveals the same pattern - biological concepts are popular in all three countries and biology enjoys higher popularity among the girls in Norway and England than in Nigeria. Chemistry is only popular to Nigerian girls. Physics appears as the most unpopular subject for both boys and girls in all three countries (Sjøberg 2002).

These results are not surprising and are very much inconsistent with what stereotypically is considered girls' and boys' interests. Physics is considered a more masculine (hard) subject like mathematics and engineering and biology is considered a more feminine (soft) subject by many of the researchers like Kelly, 1978, and Weinreich, 1977 (cited in Steinkamp and Maehr, 1983). As Sjøberg (2002, p 59) explains, 'when it comes to the interests in science topics, it seems that 'girls are girls' and 'boys are boys' - rather independent of their backgrounds.'

\section{DISCUSSION AND CONCLUSION}

The results of all the studies may be summarized as follows:

1. Students in developed countries show little or moderate interest in science; on the other hand, children in developing countries appear to be more interested in the sciences.

2. Overall, a high proportion of students in every country show positive or very positive attitudes toward science.

3. Generally, no or small gender differences are found among students' attitude variables. Some studies show significant differences, which is mostly in favour of boys.

4. East Asian students, particularly from Japan and Korea, consistently rank lowest in their attitude scores in all comparisons.

5. Overall, attitudes of student are most positive toward biology as compared to chemistry and physics.

6. The number of students taking interest in science subject areas has increased through the years in TIMSS studies.

7. Girls have a strong inclination toward biology and boys toward physics.

This literature review highlights the fact that many of the papers reviewed in this study only give data about the level of attitude and its dimension - positive or negative. However, they are missing the factors that determine these attitudes. They do not answer the questions of why students in different countries behave the way they do and how and when these attitudes change. The current database in the field critically highlights the important and fertile areas of research that require consideration from researchers.

Comparing the available attitude data is not simple and straight forward. Therefore, researchers need to develop an adequate framework for designing a more standardized way of collecting data. It needs complete, comparable, and reliable information for monitoring trends and changes in attitude throughout the world to answer many questions not currently addressed in current research literature.

Most important is the issue of making school science more interesting, meaningful, and relevant to students' lives for increasing their enrolment and retention in the field. It is quite positive of some developing nations that the students are very inclined toward the subject, but policy makers need to look into the outdated textual curriculum and replace it with a more challenging content that involves latest developments in the field of science and technology to meet the challenges of the $21^{\text {st }}$ century. 
In terms of gender differences, it would not be wise to take these differences between the interests of girls and boys permanent and innate. Instead, for attracting both boys and girls in all science subject areas, a more gender fair curriculum is necessary as well as looking into students' perceptions of the subjects as being hard or easy and useful so that an even intake of students could be possible in all subject areas.

Almost all studies have shown a reliance on quantitative methods based on questionnaires. Osborn (2003) states that a common criticism of all attitude scales derived from such instruments is that while they are useful in identifying the nature of the problem, they have been of little help in understanding it. A multi-method approach involving quantitative and qualitative research efforts may be better. Moreover, qualitative approaches will help researchers explore and completely understand the determinants of attitudes.

The relationship of background variables - attitude and change of attitude across cultures - is an important field to be explored. Other researches should study the students' parents and teachers in order to get a better understanding of their attitudes and beliefs and how they influence their children's understandings.

\section{ACKNOWLEDGEMENTS}

We are deeply indebted to Professor Sally Hartley for her stimulating encouragement to write this review. We also want to thank Dr. Malcolm Seddon for all his help, support, interest and valuable suggestions.

\section{REFERENCES}

1. Beaton, A. E., Martin, M.O., Mullis, I.V.S., Gonzales, E.J., Smith, T.A., \& Kelly, D.L. (1996). Science Achievement in the Middle School Years: IEA's TIMSS. Chestnut Hill, MA: Boston College.

2. Blalock, C. L., Lichtenstein, M., Owen, S., Pruski, L., Marshall, C., \& Toepperwein, M. (2008). In Pursuit of Validity: A comprehensive review of science attitude instruments 1935-2005. International Journal of Science Education, 30 (7), 961- 977.

3. Brok, P., Fisher, D., \& Scott, R. (2005). The importance of teacher interpersonal behaviour for student attitudes in Brunei primary science classes. International Journal of Science Education, 27 (7), 765 - 779.

4. $\quad$ Fraser, B. J. \& Kahle, J.B. (2007). Classroom, Home and Peer Environment Influences on Student Outcomes in Science and Mathematics: An analysis of systemic reform data. International Journal of Science Education, 29 (15), 1891-1909.

5. George, R. (2006) A Cross-domain Analysis of Change in Students' Attitudes toward Science and Attitudes about the Utility of Science. International Journal of Science Education. 28: (6), 571-589

6. Havard, N. (1996). Student attitudes to studying A-level sciences. Public Understanding of Science, 5, 321330.

7. House of Commons, (2002). Science Education from 14-19: third report of session 2001-02. Volume 1: Report and Proceedings of the Committee. London: The Stationery Office. Retrieved April 30, 2008 from http://www.parliament.uk/commons/selcom/s\&tpnt37.htm

8. Leung, F. S. (2002). Behind the High Achievement of East Asian Students. Educational Research and Evaluation, 8 (1), 87-108.

9. Lyons, T. (2006). Different Countries, Same Science Classes: Students' experiences of school science in their own words. International Journal of Science Education, 28 (6), 591-613.

10. Martin, M.O., Mullis, I.V.S., Beaton, A.E., Gonzalez, E.J., Smith, T.A., \& Kelly, D.L. (1997). Science achievement in the primary school years: IEA 's Third International Mathematics and Science Study. Chestnut Hill, MA: Boston College.

11. Martin, M. O., Mullis, I.V.S., \& Foy, P. (2008). TIMSS 2007 International Mathematics Report: Findings from IEA's Trends in International Mathematics and Science Study at the Fourth and Eighth Grades. Chestnut Hill, MA: TIMSS \& PIRLS International Study Center, Boston College.

12. Martin, M. O., Mullis, I.V.S., Gonzalez, E.J., \& Chrostowski, S.J. (2004). Findings from IEA's Trends in International Mathematics and Science Study at the Fourth and Eighth Grades. Chestnut Hill, MA: TIMSS \& PIRLS International Study Center, Boston College. 
13. Martin, M. O., Mullis, I., Gonzalez, EJ., Gregory, KD., Smith, TA., Chrostowski, SJ., et al. (2000). TIMSS 1999 International Science Report Findings from IEA's Repeat of the Third International Mathematics and Science Study at the Eighth Grade. Chestnut Hill, MA: Boston College.

14. Mullis, I.V.S., Martin, M.O., Beaton, A.E., Gonzalez, E.J., Kelly, D.L., \& Smith, T.A. (1998). Mathematics and science achievement in the final year of secondary school. IEA 's Third International Mathematics and Science Study. Chestnut Hill, MA: Boston College.

15. Murphy, C. \& Beggs, J. (2001, September). Pupils' attitudes, perceptions and understanding of primary science: comparisons between Northern Irish and English schools. Paper presented at the Annual Conference of the British Educational Research Association, University of Leeds, England.

16. Murphy, C., Ambusaidi,A., \& Beggs, J. (2006). Middle East meets West: Comparing children's attitudes to school science. International Journal of Science Education, 28 (4), 405-422.

17. OECD (2006). PISA 2006 Science Competencies for Tomorrow's World. Paris: OECD.

18. Osborne, J., Simon, S. \& Collins, S. (2003). Attitudes towards science: A review of the literature and its implications. International Journal of Science Education, 25, 1049-1079.

19. Papanastasiou, C. \& Michalinos, Z. (2004). Differential effects of science attitudes and science achievement in Australia, Cyprus, and the USA. International Journal of Science Education, 26 (3), 259280.

20. Schreiner, C. \& Sjøberg, S. (2007). Science education and youth's identity construction - two incompatible projects? In D. Corrigan, Dillon, J. \& Gunstone, R. (Eds.), The Re-emergence of Values in the Science Curriculum. Rotterdam: Sense Publishers.

21. Sjøberg, S. (2002). Science for the children? Report from the Science and Scientist-project. Acta Didactica, 1/2002, Department of Teacher Education and School Development, University of Oslo. Retrieved April 20, 2008 from http://folk.uio.no/sveinsj/sas_report_new\%20.pdf

22. Smith, T. A., Martin, M.O., Mullis, I.V.S., \& Kelly, D.L. (2000). Profiles of Student achievement in Science at the TIMSS International Benchmarks. TIMSS International Study Centre Lynch School of Education BOSTON COLLEGE Chestnut Hill, Massachusetts.

23. Stefánsson, K. K. (2006). 'I just don't think it's me' A study on the willingness of Icelandic learners to engage in science related issues Unpublished Doctoral dissertation, Department of Teacher Education and School Development, University of Oslo, Norway.

24. Trumper, R. (2006). Factors Affecting Junior High School Students' Interest in Biology Science Education International, 17 ( 1), 31-48.

25. Weinburgh, M. H. (1995). Gender Differences in Student Attitudes toward Science: A Meta-Analysis of the Literature from 1970 to 1991. Journal of Research in Science Teaching, 32, 387-398

26. Ye, R., Wells, R., Talkmitt, S., \& Ren, H. (1998, April). Student Attitudes toward Science Learning: A cross-National study of American and Chinese Secondary School Students. Paper presented at the Annual Meeting of the National Science Teachers Association Las Vegas, NV. 